\title{
Review of: "Effect of COVID-19 pandemic on grade inflation in higher education in Turkey"
}

\author{
ABDULLAH ORTADEVECI
}

Potential competing interests: The author(s) declared that no potential competing interests exist.

The present study investigates the grades taken by a total of 302,288 students from five different universities in Turkey in both pre-pandemic period (PPP) and during the pandemic settings (PS). As a result of this comprehensive study, it was determined that the grades in PPP increased by $9.1 \%$ compared to the ones in PS. This increase rate is the highest grade inflation rate among relevant studies conducted so far. This study, suggests that the grade inflation might stem from instructors' tendency to grade higher to compensate for the unforeseen negative consequences of distance education.

The study was conducted with a successful planning and a strong sample size. The data used in the study were obtained from a reliable source (universities). In addition to examining the data as a whole, other variables such as fields, class population, instructor's academic history, class level, university entrance scores, types of conducting courses and evaluation were taken into consideration. However, an analysis based on the type of exam applied in PPP and PS (face to face, homework, project, presentation, etc.) could have been meaningful for the readers and made a significant contribution to the study. In this way, the grade inflation of the courses that had involved exams not requiring face-to-face contact in the PPP could have also been evaluated.

The study has revealed the rates of grade inflation by making separate evaluations according to the exam types in only PS. This analysis is very important to evaluate the grade inflation according to exam type. However, many studies have also revealed concerns about exam evaluation, grading, and exam security in online education (https://eric.ed.gov/?id=EJ1293947 - https://www.diva-portal.org/smash/record.jsf? pid=diva2\%3A1564840\&dswid=-8352 - https://link.springer.com/article/10.1007/s11092-020-09340-w). It could have been discussed in the paper that exam security and grading reliability can also affect grade inflation. In fact, as stated in the discussion part, some universities that took precautions in terms of exam security could have been included in the study and the grade inflation differences observed in these courses, if any, could be evaluated.

It is an important conclusion that the factor that causes grade inflation may have been the instructors' act of grading higher in order to compensate unexpected negative circumstances. In addition, in PS, students were socially isolated and places such as cafes, restaurants and bars where they could spend time were closed. Therefore, this could have also been considered as a factor providing them more time to study; thus, getting higher grades.

The researcher made an important contribution to the literature in terms of the examined data and the 
results obtained in this study. Thanks to this study, the fact that the COVID-19 pandemic caused grade inflation in higher education in Turkey was revealed. It will form the basis for future studies to reveal other causes of "grade inflation" and to idealize grading in online education. 